\title{
O estatuto epistemológico da agroecologia
}

\section{The epistemological statute of agroecology}

\author{
PATRÍCIA DE OLIVEIRA DOS SANTOS
}

\begin{abstract}
Resumo: Este trabalho consiste em uma explicitação sobre o estatuto epistemológico da agroecologia tendo por base as contribuições de Hugh Lacey em A controvérsia sobre os transgênicos: questões científicas e éticas de 2006. Para isso, entendendo que a base para essa discussão se dá no embate entre os chamados proponentes, que defendem o uso dos transgênicos, e os críticos, que defendem o uso de formas alternativas de cultivo como, por exemplo, a agroecologia. Serão abordados os tipos de estratégias que precisam ser adotadas para investigar empiricamente proposições como "Não existem formas alternativas de agricultura que poderiam ser desenvolvidas no lugar dos modos propostos de orientação transgênica, sem ocasionar riscos inaceitáveis" $\left(\mathrm{P}_{4}\right)$ e "Não existem formas alternativas de agricultura - no interior da trajetória do sistema sócio-econômico baseado no capital e no mercado" (P4a). A partir disso, será ressaltado a importância dos movimentos que constituem o Fórum Social Mundial (FSM), bem como dos movimentos emancipatórios, buscando ressaltar o papel dos movimentos sociais para a epistemologia da agroecologia.
\end{abstract}

Palavras-chave: Agroecologia. Proponentes. Neoliberalismo. Conhecimento. Fórum Social Mundial.

Abstract: Abstract: This work consists of an explanation of the epistemological status of agroecology based on the contributions of Hugh Lacey in The controversy on transgenics: scientific and ethical issues of 2006. To this end, understanding that the basis for this discussion occurs in the clash among so-called proponents, who advocate the use of transgenics, and critics, who advocate the use of alternative forms of cultivation, such as agroecology. The types of strategies that need to be adopted to empirically investigate such proposals as "There are no alternative forms of agriculture that could be developed in place of the proposed modes of transgenic guidance without causing unacceptable risks" $\left(\mathrm{P}_{4}\right)$. In addition, "There are no alternative forms of agriculture - within the trajectory of the socioeconomic system based on capital and the market "( $\left.\mathrm{P}_{4} \mathrm{a}\right)$. From this, it will be emphasized the importance of the movements that make up the World Social Forum (WSF), as well as the emancipatory movements, seeking to emphasize the role of social movements in the epistemology of agroecology.

Keywords: Agroecology. Proponents. Neoliberalism. Knowledge. World Social Forum.

Este trabalho busca fazer uma explicitação sobre o estatuto epistemológico da agroecologia. Para isso, será tomado por base as contribuições de Hugh Lacey em $A$ controvérsia sobre o uso dos transgênicos: questões cientificas e éticas de 2006. Como o próprio título sugere, nessa obra Lacey tem por objetivo discutir questões científicas e éticas relacionadas a controvérsia sobre o uso e a implementação imediata dos alimentos transgênicos. A base para essa discussão se dá no embate entre os chamados proponentes, que defendem o uso dos transgênicos, e os críticos,

\footnotetext{
${ }^{1}$ Graduada em Filosofia pela Universidade Estadual do Centro-Oeste do Paraná - UNICENTRO. Email: patyyoliveirasant@hotmail.com.
} 
que defendem o uso de formas alternativas de cultivo tal como a agroecologia. Se por um lado encontramos os proponentes, dispostos a defender a todo custo o uso de alimentos transgênicos com a justificativa de que eles são necessários para acabar com a fome no mundo, por outro lado encontramos aqueles que defendem que é necessário mais pesquisa antes de se tomar uma decisão definitiva e que existem formas alternativas de agricultura.

Deve-se depreender que este trabalho leva em consideração o fato de que há valores e interesses opostos nesta discussão, mas como o objetivo principal é demonstrar o estatuto epistemológico da agroecologia, ainda que mencionando alguns valores pertinentes, parte-se das seguintes questões: por que a agroecologia é considerada por muitos como mera ideologia? Quais fatores podem sustentar essa alternativa aos transgênicos? Com base nessa questão, serão analisados esses fatores necessários e a relação com os argumentos $\mathrm{P}_{4}$ - "Não existem formas alternativas de agricultura" - e $\mathrm{P}_{4} \mathrm{a}$ - "Não existem formas alternativas de agricultura - no interior da trajetória do sistema sócio-econômico baseado no capital e no mercado [...]." (LACEY, 2006, p. 174). A partir disso, se fará indispensável demonstrar a importância do Fórum Social Mundial (FSM) e dos movimentos emancipatórios, pois estes movimentos, contribuem de forma direta para o teste empírico das formas alternativas de agricultura e, de modo especial, da agroecologia e de sua epistemologia.

Inicialmente, em seu argumento $\mathrm{P}_{4}$, os proponentes afirmam categoricamente não haver formas alternativas de agricultura e que os transgênicos são necessários para alimentar o mundo (LACEY, 2006, p. 149). Entretanto, os críticos contraargumentam que existem formas alternativas de agricultura que estão sendo desenvolvidas e que podem ser consideradas mais sustentáveis, que protegem a biodiversidade e que possuem o potencial de produzir em larga escala. O que mais chama atenção é o fato de que o lado proponente parece ser um tanto quanto dogmático em relação ao lado crítico, simplesmente por não utilizarem as mesmas estratégias na condução da pesquisa científica. Precisamente, conforme Wolfe:

Por que essa abordagem não é amplamente adotada? É simples demais, não faz uso o bastante de alta tecnologia? [...]. Misturas de variedades podem não fornecer todas as respostas aos problemas de controle de doenças e produção estável da agricultura moderna. Mas seu desempenho até aqui em situações experimentais merece que sejam mais amplamente empregadas (WOLFE, 2000, p. 681682).

Basicamente, têm-se uma enorme diferença quando o assunto são estratégias, a saber, o lado proponente é compreendido como a "agricultura do futuro" e, por isso, não é novidade que as pesquisas científicas sejam conduzidas de acordo com estratégias da pesquisa científica moderna (quase que exclusivamente de acordo 
com estratégias materialistas), bem como a valorização moderna do controle; por outro lado, para os críticos, as pesquisas científicas precisam ser conduzidas de acordo com uma pluralidade de estratégias e, a rigor, estratégias que incluam valores da participação popular e que levem em conta o contexto sociocultural de cada ambiente. $\mathrm{O}$ fato é que, a agroecologia é tomada por vezes como mera ideologia ou estilo de vida, e quando se trata de analisar sua viabilidade ou legitimidade parece ser até mesmo ignorada. Ao contrário disso, a agroecologia pode ser entendida como uma das principais formas de alternativas de agricultura e analisando sua viabilidade ou legitimidade, trata-se de uma proposta consolidada. Mas, se é uma proposta consolidada por que não é vista como tal?

Ora, apesar de ser uma proposta consolidada, a agroecologia vai muito além da simples adoção de estratégias materialistas na condução da pesquisa científica. Segundo Altieri, a agroecologia "utiliza os agroecossistemas como unidade de estudo, ultrapassando a visão unidimensional - genética, agronomia, edafologia incluindo dimensões ecológicas, sociais e culturais" (ALTIERI, 2004, p. 23). Com isso, o conhecimento obtido através dessa forma alternativa, é o conhecimento no qual pesquisadores e agricultores interagem entre si, a troca de saberes é, nesse âmbito, um dos requisitos básicos para a discussão e elaboração (e portanto, assegura-se como democrática) de teorias e hipóteses que fundamentem ainda mais a viabilidade dessa forma alternativa de agricultura. Entretanto, embora a troca de conhecimento entre pesquisadores e agricultores, bem como a pluralidade de estratégias sejam os objetivos principais da agroecologia, o lado proponente parece não compreender o que realmente está em jogo. Segundo Santilli, "os saberes agrícolas passaram a ser produzidos fora do campo, longe dos agricultores, pelas instituições de pesquisa" e por isso, "os agricultores foram convertidos em "meros usuários finais do trabalho desenvolvido pelos técnicos do melhoramento vegetal"” (SANTILLI apud BARROS; ARAÚJO, 2016, p.88). Ademais, o comprometimento com o éthos científico pelos proponentes, acaba por obscurecer a visão sobre os críticos.

É importante ressaltar que os críticos não estão rejeitando o conhecimento obtido por meio de pesquisas conduzidas sob estratégias materialistas, nem mesmo de pesquisas feitas em laboratórios. Para os críticos, o que está em jogo é a adoção de uma pluralidade de estratégias e, por isso mesmo, adotar apenas uma perspectiva é limitar-se a um campo de conhecimento fechado. Por causa desse posicionamento, os críticos são acusados de ir contra o "progresso da ciência" e da própria tecnologia; são acusados de adotar, a rigor, uma posição "anticiência". O grande problema dessa visão pessimista, que os proponentes possuem em relação à agroecologia, deve-se ao papel que se atribui a ciência, as pesquisas científicas e ao próprio conhecimento científico moderno. Dado que a ciência e as pesquisas científicas são baseadas na valorização moderna do controle e em estratégias materialistas, o próprio conhecimento científico fica restrito a dados quantitativos, deixando de lado outras 
formas de conhecimento que também podem contribuir para o avanço das investigações. Nesse sentido, segundo Lacey, "embora não se negue que os Tgs são produto de um conhecimento científico seguro, questiona-se o lado-P de que esse tipo de conhecimento é geralmente exemplar" (LACEY, 2006, p. 161). Não obstante, mesmo sendo notável o avanço da tecnociência e a rápida difusão de alimento transgênicos, as controvérsias subjacentes a questão da implementação desses alimentos, demonstram que para se legitimar os transgênicos de forma definitiva não basta apenas requerer a "autoridade da ciência"; antes, é preciso que o próprio argumento central dos proponentes seja submetido ao teste empírico.

Nessa perspectiva, se considerado o argumento $\mathrm{P}_{4}$, que defende não haver formas alternativas de agricultura, para que esse argumento seja endossado, é preciso antes investigar $\mathrm{C}_{4}$ ("Existem formas alternativas de agricultura"), somente se $_{4}$ falhar em provar a viabilidade ou legitimidade de outras formas de agricultura é que $\mathrm{P}_{4}$ poderia requerer o input científico e consolidar-se como a "agricultura do futuro". Entretanto, segundo Lacey: "As práticas que expressam os valores de "sustentabilidade" penetram no cerne do projeto neoliberal e, nestes dias de triunfalismo do mercado, possibilidades alternativas são facilmente descartadas" (Ibidem). Por isso, devido a primazia das estratégias materialistas baseadas no capital e no mercado, a agroecologia enquanto uma das principais formas alternativas de agricultura, não consegue investimento ou financiamento adequado de suas pesquisas justamente por ir contra o neoliberalismo dominante da modernidade, permanecendo assim em segundo plano ou sendo simplesmente rejeitadas.

A partir disso, é possível compreender a inserção do argumento P4a - "Não existem formas alternativas de agricultura - no interior da trajetória do sistema sócio-econômico baseado no capital e no mercado [...] e fora dessa trajetória não há possibilidades genuinamente realizáveis" (LACEY, 2006, p. 174). Tal argumento releva que o que está em jogo são condições socioeconômicas, e diante disso, como os países subdesenvolvidos ou em desenvolvimento podem defender formas alternativas de agricultura? Está claro que as inovações científicas-tecnológicas estão presentes predominantemente nos países desenvolvidos, e justamente por isso, possuem grande adesão de corporações que passam a financiar pesquisas de alimentos transgênicos em prol do velho jargão "em time que está ganhando não se mexe". Os transgênicos são, pois, o exemplo mais bem-sucedido do resultado das pesquisas científicas conduzidas por estratégias materialistas. Com base nisso, para que a viabilidade ou legitimidade da agroecologia possa ser sustentada, "não é suficiente produzir evidências do potencial produtivo da agroecologia: é necessário torná-la socialmente viável em ampla escala" (LACEY, 2007, p. 39). Essa viabilidade pode ser confirmada pelos movimentos emancipatórios e os movimentos que compõem o Fórum Social Mundial (FSM). 
Nesse âmbito, Lacey traz a luz os três fatores que sustentam ou podem sustentar a agroecologia e o conhecimento obtido por meio da pluralidade de estratégias na pesquisa científica. Segundo ele, os três fatores se sustentam e por esse motivo, se algum deles "falha" "não se desenvolve" adequadamente, os outros dois fatores são afetados diretamente, ocasionando obstáculos até mesmo insuperáveis. Esses fatores podem ser assim enunciados:

O êxito da condução da pesquisa segundo as estratégias agroecológicas, a expansão e o aperfeiçoamento da agricultura agroecológica e as atividades e o crescimento dos movimentos que incorporam os valores da participação popular estão inseparavelmente interligados (LACEY, 2006, p. 181).

A análise destes fatores demonstra que a combinação de ambos garante uma força tal a agroecologia, que essa forma alternativa passa a caminhar lado a lado com às inovações dos transgênicos, sendo possível comparar ou até mesmo competir com elas. Ademais, é possível considerar que os movimentos sociais são de grande importância para o êxito da condução de pesquisas agroecológicas. Dado que a agroecologia inclui valores como os da participação popular e da localização sociocultural, na medida em que ocorre a expansão dos movimentos sociais, há também um desenvolvimento significativo de teorias, hipóteses, testes, troca de saberes entre cientistas e agricultores, concentração de pesquisas locais, garantia de direitos sociais, etc; logo, tem-se a incorporação de valores que não remetem meramente a termos mercadológicos e/ou lucrativos, mas se pretendem ser (e são) o oposto à isso.

Ademais, segundo Lacey, os transgênicos são conduzidos segundo estratégias materialistas, mas não se pode negar que a eficácia da tecnologia transgênica tem sido confirmada (LACEY, 2006, p. 181). No entanto, mesmo que sua eficácia venha se confirmando, ainda não se tem garantias dos riscos a curto e longo prazo dos mesmos e o interesse maior sempre seria baseado na lucratividade, tal como pressupõe a variação $\mathrm{P}_{4}$ a. $\mathrm{O}$ grande problema em abandonar a investigação de $\mathrm{C}_{4}$, por exemplo, estaria em endossar um argumento (o $\mathrm{P}_{4} \mathrm{a}$ ) que admitiria que a legitimidade do uso dos transgênicos em larga escala dependeria somente de um fator mercadológico, e não mais de pesquisa científica. Caso isso fosse considerado um fato consumado e indiscutível, o lado $P$ poderia, de fato, reivindicar a autoridade da ciência, passando esta a ser conduzida em termos de capital e mercado (LACEY, 2006, p. 182). Mas, e o conhecimento científico reivindicado pelos proponentes como requisito mínimo para o lado-C? Se os proponentes acusam os críticos de serem "anticientíficos" por não se restringirem a estratégias materialistas e darem ênfase a um tipo de pesquisa que engloba vários tipos de conhecimentos (local, social, cultural, etc.), o que dizer dessa posição dogmática adotada pelos defensores dos transgênicos? Há perspectivas que não contenham valores de capital e de 
mercado e que carreguem um conjunto de conhecimentos e investigações empíricas suficientes para confirmar sua legitimidade ou viabilidade?

No que se refere a esta última questão, pode-se encontrar movimentos que contenham valores da participação popular, e que são contrários a valores como os mercadológicos. Um dos principais movimentos que merece uma atenção especial é o chamado Fórum Social Mundial (FSM), o qual tem por lema "outro mundo é possível" e que busca demonstrar que há outra alternativa à trajetória do capital e do mercado. No que diz respeito ao FSM, este movimento iniciou-se em Porto Alegre em Janeiro de 2001 com intuito de contrapor-se ao Fórum Econômico Mundial de Davos, mais tarde com a Carta de Princípios, o movimento acabou sendo garantido como um espaço e processo permanente de busca de construção de alternativas em âmbito mundial (FSM, 2001). Conforme Boaventura de Sousa Santos (2004, p. 9):

O FSM é o conjunto de iniciativas de intercâmbio transnacional entre movimentos sociais, organizações não-governamentais (ONGs), e os seus conhecimentos e práticas das lutas sociais locais, nacionais e globais, levadas a cabo em conformidade com a Carta de Princípios de Porto Alegre contra as formas de exclusão e de inclusão, de discriminação e igualdade, de universalismo e particularismo, de imposição cultural e relativismo, produzidas ou permitidas pela fase actual do capitalismo conhecida como globalização neoliberal.

Nesse sentido, o FSM ao ter como lema "Outro mundo é possível" não quer apenas demonstrar que há uma alternativa, mas, a rigor, que há uma alternativa científica que se opõe fortemente ao neoliberalismo. Segundo seus integrantes, o neoliberalismo é um tipo de opressão e é preciso se libertar desta opressão, pois em suas estruturas e sob o manto da "globalização", estão cada vez mais absorvendo mais e mais espaço econômico, social e cultural (LACEY, 20o6, p. 193). Com isso, o FSM surge como um movimento que busca a emancipação. Também objetiva fazer uma crítica ética do atual mundo social, ou seja, para seus defensores, só se pensa no capital e no mercado (visando exclusivamente o lucro) e se esquece do ser humano, de seus valores éticos, morais e das riquezas culturais. Dessa forma, os integrantes do FSM trazem consigo um imperativo para que esse mundo que almejam ou desejam, se torne realidade.

Por conseguinte, para compreender o que significa esse imperativo é preciso antes compreender a importância dos movimentos emancipatórios. Isso porque os movimentos que incorporam o FSM se caracterizam como emancipatórios. Esses movimentos são, por sua vez, a chave para o desenvolvimento de mais e mais movimentos parecidos ou semelhantes com o FSM. Com base nisso, a primeira coisa a ser considerada é a capacidade de ação do indivíduo. Segundo Lacey (2006, p. 186), "a dimensão fundamental do bem-estar humano é o exercício da capacidade de ação cultivada e eficaz que é exercida quando as pessoas agem em aspectos importantes 
de suas vidas informadas por suas crenças". Nesse sentido, quando uma pessoa possui uma crença tal como um valor ético que considera como uma característica fundamental para considerar sua vida "bem vivida", esse valor (e outros) é incorporado e passa a ser condição necessária para uma vida digna. A grande questão é que a capacidade de ação contém uma variedade de condições, tais como, que crenças derivadas da ação de um indivíduo são verdadeiras e que um indivíduo tenha acesso e controle sobre objetos tecnológicos, etc. Entretanto, o próprio Lacey afirma que "quando essas condições para a capacidade de ação não são satisfeitas, ela é enfraquecida” (Ibidem). Com isso, a capacidade de ação acaba se tornando um fenômeno social relevante pelo fato de que ela gera "sofrimentos".

Esses sofrimentos por sua vez, são a frustação, a depressão, entre outros problemas que podem gerar um mal-estar. Essa combinação da capacidade de ação enfraquecida e os sofrimentos decorrentes dela, geram a opressão. Sendo que, aqueles indivíduos que se encontram nessa opressão desejam ser livres e desamarrar as cordas da opressão, ou seja, desejam chegar a uma emancipação. Contudo, para que a emancipação ocorra é necessário a transformação estrutural, que serve somente se ela produz estruturas que envolvem valores que sejam livremente sustentados por aqueles que a querem. Sendo assim, a opressão enquanto fenômeno social relevante, é derivada de estruturas sociais que não fornecem condições para a capacidade de ação efetiva para todos os seus participantes; em outros termos, a estrutura social favorece somente alguns de seus participantes, e não todos. Dessa forma, o problema é: como a emancipação é possível onde a estrutura social é o maior causador da opressão? (LACEY, 2006, p. 188). A resposta para esta questão pode ser encontrada nela mesma pois, emancipação e opressão são coisas distintas, mas só há desejo de emancipação quanto há opressão. Mesmo assim, ainda é preciso compreender o que significa uma estrutura social.

Segundo Lacey, uma estrutura social é um conjunto de relações mais ou menos duradouras entre seus participantes que definem os papeis ou lugares para a atividade de seus participantes (Ibidem). A estrutura social reflete as ações dos chamados agentes, que são os participantes dessa estrutura sendo que, os papeis dos agentes são o resultado da ação intencional dos mesmos, que podem ou não estar conscientes. Além disso, a estrutura social manifesta valores populares ou sociais que têm profunda relação com à distribuição da riqueza, do conhecimento científico, etc. Dado que há uma mútua relação entre esse tipo de estrutura e os participantes, é preciso um respeito mútuo entre os próprios participantes, assim como valores sociais, pessoais e éticos mais ou menos parecidos. Porém, isso não significa que não pode haver manifestação de valores concorrentes em uma estrutura social. Aqui, é possível perceber uma certa relação com Thomas Kuhn e suas noções de comunidade científica e paradigma. Tal fato parece se assemelhar com essas noções, por haver uma mudança na própria estrutura e haver a abertura 
para que as crenças que um indivíduo possui para sustentar certos valores sejam alimentadas; logo, há uma abertura para se convencer os demais participantes a compartilharem dos mesmos valores e, quanto a essa colaboração dos que se solidarizam, é justamente nesse momento que emerge ou ressurge a capacidade de ação efetiva como uma grande força. Diante disso, será necessária uma nova estrutura social, baseada em novos valores que consideram necessários, tais como a participação democrática.

Contudo, ainda permanece a questão de como investigar empiricamente “outro mundo é possível”. Primeiramente, o FSM como forte contraposição ao neoliberalismo, mantém todos os anos seus encontros internacionais. Nesse evento, há a troca de conhecimento entre seus participantes, novas estratégias são apresentadas, novos estudos relacionados, novas teorias fundamentadas enfim, há uma espécie de entendimento científico (sistemático, empírico, prático) que procura, por exemplo, fortalecer cada vez mais os movimentos, incentivar mais pesquisas voltadas as práticas sustentáveis, favorecer a participação democrática e, principalmente, sustenta-se como alternativa. Em 2018, a Carta das Convergências Agroecológicas do Fórum Social Mundial relatou sobre sua evolução:

O Movimento Agroecológico evoluiu das iniciativas da agricultura alternativa e desde o início, as organizações sociais e instituições de pesquisa, ensino e extensão envolvidas com sua construção, primaram por reconhecer, resgatar, sistematizar e disseminar suas propostas sempre cooperativamente com as famílias, organizações e movimentos da agricultura familiar camponesa, dos povos indígenas e das comunidades tradicionais e agroextrativistas, baseando-se nos conhecimentos e práticas centenárias e milenares em extrativismo, cultivos, criatórios, beneficiamentos e consumos saudáveis e solidários, de alimentos e para usos medicinais, artesanais, ornamentais e ritualísticos (FSM, 2018, p. 3).

Nessa perspectiva, o FSM enquanto um exemplo de movimento da agroecologia e enquanto prática científica, está disseminada em alguns tipos de contexto, tais como o ensino, a inovação, a avaliação e a aplicabilidade. No que tange ao ensino, é possível compreender que a formação do indivíduo perpassa por uma espécie de resgate da própria história da ciência, dos métodos empregados na agricultura, por exemplo, pelos antepassados, pela tradição. Com relação a inovação, há a produção do conhecimento teórico, empírico e técnico, no qual a valorização se dá por critérios como a generalidade, a coerência, a consistência e a validez (CAPORAL; AZEVEDO, 2011, p. 26). Já a avalição, diz respeito aos testes e aplicações dos métodos científicos, bem como a participação democrática dos membros. Por fim, com relação ao contexto da aplicabilidade, o que se tem é o resultado da relevância social e econômica da própria agroecologia. 
Não obstante, os movimentos que incorporam o FSM questionam o "senso comum" do neoliberalismo justamente porque esse "senso comum" limita a compreensão da diversidade ou da pluralidade, limitando não só o fenômeno social como também o próprio conhecimento científico, que não ocorre sem a aceitação dialógica e dialética do outro e da diferença (CAPORAL; AZEVEDO, 2011, p. 27). Nesse sentido, o "senso comum" do neoliberalismo revela uma espécie de "certeza ideológica" pautada pelas pressuposições da valorização moderna do controle, visões individualistas, contínua expansão das produções em larga escala, etc. $\mathrm{O}$ resultado disso é, pois, um sistema "incapaz de responder à função primária da economia: prover a base da vida física e cultural de todos os humanos do planeta" (FSM, 2002 apud LACEY, 2006, p.196). Por isso, em conformidade com a visão de Boaventura de Sousa Santos (1995, p. 33-49), o conhecimento natural é também o conhecimento social o que implica em incorporar estratégias contextualizadas em pesquisa científica, levar em consideração o conhecimento local, compreender o conhecimento como "autoconhecimento" e promover o diálogo entre os vários tipos ou formas de saber (teórico e prático).

Nesse âmbito, segundo Caporal, Norgaard (1989) conseguiu resumir as bases epistemológicas da agroecologia da seguinte forma:

a) os sistemas biológicos e sociais têm potencial agrícola; b) este potencial foi captado pelos agricultores tradicionais através de um processo de tentativa, erro, aprendizado seletivo e cultural; c) os sistemas sociais e biológicos coevoluíram de tal maneira que a sustentação de cada um depende estruturalmente do outro; d) a natureza do potencial dos sistemas social e biológico pode ser melhor compreendida dado o nosso presente estado do conhecimento formal, social e biológico, estudando-se como as culturas tradicionais captaram este potencial; e) o conhecimento formal, social e biológico, o conhecimento obtido do estudo dos sistemas agrários convencionais, o conhecimento de alguns insumos desenvolvidos pelas ciências agrárias convencionais e a experiência com instituições e tecnologias agrícolas ocidentais podem se unir para melhorar tanto os agroecossistemas tradicionais como os modernos; f) o desenvolvimento agrícola, através da Agroecologia, manterá mais opções culturais e biológicas para o futuro e produzirá menor deterioração cultural, biológica e ambiental que os enfoques das ciências convencionais por si sós (CAPORAL; COSTABEBER.; PAULUS, 2009, p. 21-22).

Com isso, embora haja uma diferença entre o conhecimento considerado "convencional" ou "científico" e o conhecimento "prático" ou "cotidiano", para a agroecologia, esses tipos de conhecimento deverem interagir entre si. Não há como negar a importância do conhecimento "científico", embora ignorar conhecimentos "cotidianos" implique uma limitação e um "senso comum" prejudiciais a própria ciência. Evidentemente, a tendência é considerar, nesse caso, a ciência como algo 
fechado, sistemático e dotado de uma autoridade capaz de dizer "verdades", embora por detrás contendo "certezas ideológicas". Num sentido complexo, a agroecologia vê a ciência como sistemática, fundamentada por evidências empíricas, dotada de teorias bem fundamentadas, mas reconhece o valor do conhecimento popular, local, "cotidiano", o conhecimento adquirido quando as práticas agroecológicas evoluam ou se aprimorem e o conhecimento participativo ou democrático, obtido através da articulação do conhecimento prático com o teórico, da troca de estratégias entre os participantes dos movimentos, culminando assim em uma interdisciplinaridade.

Portanto, afim de provar “outro mundo é possível”, é preciso encontrar estratégias para investigar estruturas sociais, o que motiva a origem dessas estruturas, a capacidade que elas possuem de se manter como oposição as estruturas neoliberais, bem como o potencial de provocar modificações nas estruturas vigentes. Todos esses fatores devem ser relatados ou informados pelos próprios movimentos, que baseados em recursos conceituais conseguem analisar o desenvolvimento ou retrocesso dos movimentos sociais. Tudo isso deve ser levado em conta pelo fato de que a única evidência empírica forte para provar que "outro mundo é possível”, é a própria expansão e desenvolvimentos dos movimentos emancipatórios. Dessa forma, fica claro que essas estratégias a serem adotadas encontram um mútuo reforço com a manifestação dos valores da participação popular presentes nos movimentos emancipatórios. Com isso, ressalta-se a importância dos movimentos que constituem o FSM uma vez que estes são exemplos de formas alternativas capazes de questionar o "senso comum" do neoliberalismo e ainda defender a sustentabilidade, a biodiversidade, valores éticos, sociais e socioculturais; logo, demonstrar um conjunto de conhecimentos bem fundamentados e a promover a defesa de uma pluralidade epistemológica na própria agroecologia.

\section{Referências}

ALTIERI, M. Agroecologia: a dinâmica produtiva da agricultura sustentável. 4.ed. Porto Alegre: Editora da UFRGS, 2004.

BARROS, E. P.; ARAÚJO, A. "Agroecologia e transdisciplinaridade: considerações acerca da crítica ao enfoque técnico-científico da Revolução Verde”, in: Ciências Sociais em Perspectiva, v.15 - no. 28: p. 83 - 95; 1ํㅗ. sem. 2016.

CAPORAL, F.R; AZEVEDO, E. O. Princípios e perspectivas da Agroecologia. Instituto Federal de Educação, Ciência e Tecnologia do Paraná, 2011.

CAPORAL, F. R.; COSTABEBER, J. A.; PAULUS, G. Agroecologia: uma ciência do campo da complexidade. Brasília: MDS/Embrapa, 2009.

FSM - Fórum Social Mundial. Carta de Princípios do Fórum Social Mundial, 2001. Disponível em:<http://www.universidadepopular.org/site/media/documentos/Carta_de_Principios_do _FSM.pdfs Último acesso: 29 de Outubro de 2018. 
Carta das Convergências Agroecológicas no Fórum Social Mundial, 2018. Disponível em: <http://www.moc.org.br/publicacao/geral/2743/carta-das-convergenciasagroecologicas-no-forum-social-mundial> Último acesso em: 29 de Outubro de 2018.

LACEY, H. A controvérsia sobre os transgênicos: questões científicas e éticas. Aparecida, SP: Ideias \& Letras, 2006.

“Há alternativas ao uso dos transgênicos?” In: Novos Estudos CEBRAP, São Paulo, n. 78, jul 2007, p. 31-39.

SANTOS, B. S. O Fórum Social Mundial: manual de uso. Madison, Dezembro 2004.

Ciência e senso comum. In: Introdução a uma ciência pós-moderna. Porto, Afrontamento, 1995.

WOLFE, M. S. “Crop strength through diversity”, in: Nature, vol. 406, 2000, p. 681-682.

Submissão: 30.10.2018 / Aceite: 15.12.2018. 